\title{
A LOOK AT THE ROLE OF CULTURE IN EAST-WEST DIFFERENCES IN INDECISION
}

\section{Robert A. Culpepper, Stephen F. Austin State University, U.S.A.} Fatemeh Zarei, Stephen F. Austin State University, U.S.A.

dx.doi.org/10.18374/IJBR-19-3.5

\begin{abstract}
This paper examines the research literature related to the influence of cultural factors on the phenomenon of indecisiveness. We define indecisiveness and set in the wider research context. Next, primary theorized cultural antecedents to indecisiveness are identified and discussed. These include culture-related optimism about the future, individualism and collectivism, and na ̃̃ ve dialecticalism. Finally, salient inconsistencies and contradictions in the literature regarding theory and existing empirical evidence are addressed.
\end{abstract}

Keywords: Indecision, indecisiveness, decision-making, East Asian culture 